\title{
TRAINING OF STRATEGIC DECISIONS IN COLLABORATIVE NETWORKS THROUGH SERIOUS GAMES
}

\author{
Reiner Kracke, Jannicke Baalsrud Hauge, Heiko Duin, Klaus-Dieter Thoben \\ $B I B A$ at the University of Bremen, GERMANY \\ $\{k r k$,baa,du,tho\}@biba.uni-bremen.de
}

Serious gaming is an upcoming approach for supporting training activities. Since games have been identified as an opportunity to increase familiarity of the player with any artifacts, they can also be used to mediate experience in management and strategic decision making. In combination with the current trend towards networked games, teaching of strategic decisions in collaborative network environments is the next step in the evolution of learning games. This paper presents such a gaming approach, supporting a virtual multi stakeholder environment, where trainees can experiment with new ideas without risk and effects on the real life.

\section{INTRODUCTION}

Collaborative Networks $(\mathrm{CN})$ are emerging in many business areas. Thus planning and operating them is a skill that becomes more and more important for today's professionals. In order to mediate these skills and to enable them to assess the value creation through Collaborative Networks, new forms of training for the professionals are required. An upcoming approach of training in the business world is the serious gaming approach (Prensky, 2001; Thoben et al. 2000), which uses computer games as tools to let professionals gain experience as players in a "soft failure" environment.

This paper presents an overview on the general approach of using games to support professional trainings. Based on that, a specific gaming approach focusing on training strategic decisions in manufacturing is being introduced, explaining how to achieve the projected impact in terms of learning results. Therefore it will give an overview on strategic decisions, which should be supported by serious games, and how they can be integrated in a game by providing the player with events and information, to let him freely derive his corporate strategy and decide about necessary actions, instead of leading him through a storyline. The content of this paper is based on intermediate results of the EU-project PRIME (FP6-IST-016542), which has the objective to create a game, where professionals can experiment and learn how to handle a business in a multi-stakeholder Virtual Business Environment. 


\section{TRAINING OF STRATEGIC DECISIONS}

Strategic decisions are far reaching and consequential for organizations. The importance of making the right decisions increases, when an organization is part of a collaborative network and the consequences of those decisions affect not only the own organization but also the connected partners in the network.

Strategic decisions must often be made under conditions, where parts of the environment are uncertain and assumptions about other involved parties may be incorrect or incomplete. In such situations, the decision maker has to rely on his experience to fill the gaps in the information foundation of the decision process. Additionally, decision effects are often indirect and might thus be unintended and unforeseen. At this point it's again the decision maker's experience that allows him to assess the long-term effects as well as the side-effects of his decision.

These circumstances underline the importance, that decision makers are aware of the difficulties and effects of the decision making process and in order to achieve this awareness and to provide accelerated experience, they require a special training. However, traditional vocational training methods are obviously not appropriate for this task, since experience cannot be taught in such a passive way. Instead, decision makers have to be exposed to environments and situations, where the required skills can be trained through practicing.

The real life and the real business environment would be a perfect playground to collect experience and train skills, but of course there is the problem, that the real life does not pardon failures and wrong decisions. Thus the trainees need a "soft failure" environment, where they can experiment without risking the reputation of their company or even of a whole networked organization.

\section{SERIOUS GAMES}

When coming to the point, where a model of the real world is required, computing technology usually provides solutions in form of simulation applications. Those simulations can help imitating and understanding the real world and with the ability to speed things up, long term effects can be analyzed in short time. However, simulations are not always a proper solution to support training, because their capabilities regarding interactivity are usually very limited.

A computing domain which provides extensive interactivity is the games domain. There are many genres in the computer games domain, and a special one of them is the serious game. The terminology "Serious Game" is quite new in the world of computer games and thus there's no universal definition for it, yet. However the term itself clearly states, what it is: a game with a grave background or content.

\subsection{Evolution of Serious Games}

The terminology "Serious Game" is mainly based in the computer games domain, which has experienced a rapid development in the last decades. With the introduction of personal and home computers in the 1980s, the computer games continuously gained importance in the recreational sector and with the advancing computer technology, new opportunities emerged, enabling the creation of even 
more sophisticated games (Herz, 2002). An ideal example for the development of games is the flight simulator genre. Whereas the first games of this type were very simple and just allowed the player to control an aircraft in a stylized environment with generic cockpit instruments and simple flight physics, modern flight simulators confront the player with a realistic environment including realistic cockpit instruments, realistic flight physics, a realistic world, where the landscape has been modeled using a topographic base and satellite images and even the airport towers use their real-life radio frequencies and allow in-game communication. This high degree of realism increases not only the attractiveness of the games, but it also allows the player to learn some basic about flying and thus this opportunity has been grasped by airlines and the military.

Whereas the steadily increasing computer technology can be seen as a major driver for the development of computer games, the internet and the networking capabilities in general enabled opportunities to create a new type of games: online games. The ability to play games online with other human players made games much more interesting, because a player's in-game fellows or opponents are not anymore as predictable as computer controlled ones are. Nowadays there are games, which are played by several 10.000 players at the same time - sharing a one virtual world (Ondrejka). The vast majority of online-games is still of entertaining character, but there are also some games, which have a serious and/or realistic background (Second Life). However the number of games, which address issues of learning for business life, is relative low.

\subsection{Business Games}

Business games are serious games by nature, because they're usually about managing a company, which clearly has a more serious than entertaining background. However, business games are often referred to as business simulations, where by definition a simulation is not the same as a game. A simulation's purpose is to imitate something, e.g. a flight simulator imitates the behavior of a real plane and the environment in terms of terrain and weather, but there are no elements in such a simulation that directly reflect an entertaining approach or a game's rules. In opposite to a simulation, a game always has rules and it defines a goal, which a player has to achieve in order to win the game. The reason why business games are often called business simulations might be that those games include an economic environment, which simulates the behavior of customers and competitors. But the majority of business games confront the player with a scenario and a goal, which must be achieve in order to win. This makes those games real games.

In business games the player usually has to deal with production, logistics, finance and marketing and the typical goal is to maximize the company's profit or to gain a vast market share. Even if those goals can also be found in a real company's business plan, it is a challenge for many people who like to play those types of games in their spare time. Since even the business games, which are intended for the entertainment market, have to be believable and the technical preliminaries nowadays allow a high grade of complexity in the economic system of a game, they confront the player with many terms, effects and details that can be found in the real business life. 


\subsection{Games as Training Tool}

The circumstance that a game can reflect large parts of the real world can be exploited for training purpose. Besides, using games as tool for training has some positive effects on the trainees. Even if the object of serious games is not entertainment, they are still considered as games. Thus most trainees enjoy this form of training and their involvement is more intense than in other teaching methods. Additionally games are interactive, allowing active learning, which has been proven more effective than passive learning.

The usage of serious business games for training (see Serious Games Initiative) can already be observed in schools and universities, where students can play and learn the basics of business. However this kind of training has not yet been fully established in companies. Compared to the success of flight simulators which are an established training method, business games are far from being an inherent part of business training. There are several reasons that are responsible for that difference:

- Serious business games are not obviously saving costs, like the flight simulators do. Those flight simulators reduces the training costs by using virtual airplanes for training activities, thus saving fuel and additionally it reduces the risk of failure during a pilot's first flights, because a flight simulator does not crash physically. The training of business professionals usually doesn't require expensive equipment like airplanes, thus a game is not being regarded as a cost saver.

- It is more complicated to simulate a real world business environment than the environment in a flight simulator. In a flight simulator, the trainees in the cockpit have to deal with the status of the plane and react on the environmental influences in terms of the weather condition. In a virtual business world, the state of the plane is taken by the state of the company, but the interaction and interdependencies with the environment is more complex. The complexity increases especially when the trainee acts in a collaborative network, where there are usually many stakeholders involved, whose behavior depend on the trainee's actions.

- The third big difference regards the controls, which are available to the trainee. In a flight simulator, the trainee can use the cockpit instruments, which are more or less the same in each plane. In the business world, there is no common set of controls, which allows a professional to manage a company or department, thus the companies do not see a direct relationship between serious business games and their own business, if the game has not been developed for their specific training issues.

Because of these reasons, business games still reside on the entertainment level and haven't become an inherent part of training in the business world yet. Some games may have the potential, to mediate basic knowledge of economics and can thus be used to train students on a basic level, but those games usually lack the depth of detail to be sufficient for advanced corporate training. 


\section{TRAINING OF STRATEGIC DECISIONS THROUGH NETWORKED GAMING}

\subsection{The PRIME approach}

The objective of the EU project PRIME is to create a serious business game, which can be used for advanced training of business professionals in the domain of strategic manufacturing. Thus the game is intended to be used in corporate training, the three issues of serious business games, which make the integration in professional training difficult, have to be addressed:

- To provide a set of controls, which are common to business professionals of different companies and different industries, the PRIME approach moves strategic decisions in the focus of the game. Those strategic decisions are supported in an indirect way, by providing the underlying information to the player and let him decide, what to do based on this input. This means, that there is no guide- or storyline, which leads the player through the game, querying his input at discrete turning points within the game. Instead each player has a game interface which allows him to assess the situation of his business unit and to freely decide about the necessary actions to improve his economic situation. (Decision Flows - Fig. 1)

- Even if games cannot help reducing costs in a direct way, they provide an environment, where trainees can experiment with new strategies and failures don't affect the company in the real world. PRIME aims to provide a virtual business environment (VBE) where the player can run his own business unit and gain experience through learning by doing. Especially the long term effects of strategic decisions are of interest, since a games capability to simulate those effects can provide a good feedback to the trainee, after he made a decision. (Business Units - Fig. 1)

- To provide a realistic multi-stakeholder environment, supporting collaborative networks, PRIME will be a multiplayer game, where many players share the same VBE. Whereas singleplayer games are usually based solely on simulation, the PRIME approach confronts the player not only with artificial stakeholders, but also with other human competitors and business partners. In the resulting networked gaming environment the players can communicate and interact with each other and are thus being confronted with unexpected scenarios which are influenced by the behavior and decisions of other players (Heide Smith, 2005). (Global Business Environment - Fig. 1) 


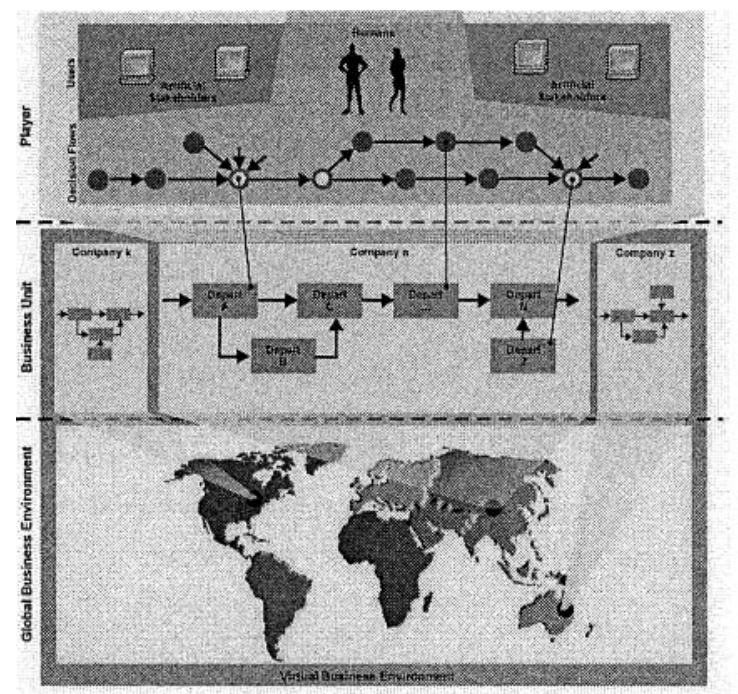

Figure 1: The Multi-Stakeholder Concept of PRIME

\subsection{Strategic decisions in PRIME}

To be of use for corporate training activities, a serious game has to provide support for the targeted training objectives. Since the PRIME approach focuses on strategic decisions, the game's qualification depends on the extent of the encompassed strategic decisions. Thus the first activity in the development of PRIME has been the compilation of a list of strategic decisions and issues, which are being regarded as important to be taught. This assessment has been done within the PRIME consortium, which not only includes developers but also end-users of the game. The following list is the result of the content related part of the user requirements analysis and shows an overview of the demanded training subjects. Additionally the training subjects have been rated by each end-user in the consortium with 1 being not important to 5 , which indicates high importance for the end-users training plans.

In order to make these decisions a part of a game, it has to provide situations where the player can decide between various options. In games, where the player is guided along a predefined storyline, these decision making points are explicit present, letting the player choose between a set of possible options. This kind of decision making is not always realistic, since in real life, there are sometimes no discrete choices and even the timing of decision making is not always given. Thus the PRIME approach is based on free decision making, where the player is always asked to assess the current situation based and act or react, when he sees a need for action. This way, a player can be as active as he wants and he can even avoid making decisions, which most probably will not improve the situation of the player's business unit. 
Table 1 - Importance of including training issues in PRIME

\begin{tabular}{|l|l|l|l|l|l|l|}
\hline Make or buy (outsourcing, off shoring) & 5 & 4 & 5 & 5 & 5 & 1 \\
\hline Customer decoupling point position & 4 & 3 & & & 4 & \\
\hline Supply/Delivery network level & 5 & 2 & 4 & 5 & 4 & 1 \\
\hline Chase vs. stocking production plan & 4 & 3 & 5 & 4 & 3 & 1 \\
\hline Stock levels; stock position (ex. bullwhip effect) & 4 & 1 & & 5 & 5 & 1 \\
\hline Integration of stakeholders (governments, NGO, etc) & 1 & 2 & 5 & 5 & & 3 \\
\hline Supplier integration (supplier vs. partners) & 2 & 2 & 4 & 5 & 5 & 1 \\
\hline Plant localisation & 5 & & 2 & 3 & 4 & 1 \\
\hline R\&D Product & 1 & 4 & 5 & 2 & 4 & 1 \\
\hline Enterprise Integration & 1 & 3 & 4 & 4 & 4 & 1 \\
\hline Manufacturing strategy & 4 & 2 & 3 & 4 & & 1 \\
\hline Modularity in products/processes & 1 & 3 & 4 & 2 & 5 & 1 \\
\hline Labour skill level & 1 & 3 & 4 & 4 & 3 & 1 \\
\hline Plant capacity & 3 & 2 & 4 & 2 & 4 & 1 \\
\hline Maintenance approaches & 1 & 4 & 3 & 2 & 2 & 2 \\
\hline Production planning strategies and methodology & 3 & 3 & 1 & 2 & 2 & 1 \\
\hline Plant/shop-floor configuration & 3 & 2 & 2 & & 1 & 1 \\
\hline
\end{tabular}

\subsection{Example for Training of "Make or Buy"}

The "Make or Buy" decision is the top rated strategic decision of the PRIME requirements list. Thus the following example is based on this type of decision, describing how the PRIME approach supports training.

As already mentioned, the player has to keep track of the current situation of his business unit. This is supported by the information, which the game provides in various ways. In case of the "Make or Buy" decision, there are information sheets, which inform the player about the costs for making a specific product. This information about costs can be either based on current costs, if the player is already producing this item, or can be estimated by the player by taking a look at the production cost of a similar product. On the other hand the player can issue an invitation to tender for the product, to get the information about costs when buying the product from a supplier. Those information sources can be regarded as direct input for the decision, but they are not being compiled for the player so he can simply choose between "make" or "buy". Besides the player has to consider other factors too, which are of an indirect nature and might not seem directly relevant for a player when making the decision. An example for this is the question, whether the item to be decided about represents a core or non-core product of the player's business unit. This question is not being asked by the game and thus must be assessed by the player. If the player runs a company, that produces cars, it might be of importance to retain the knowledge of constructing engines in the own company to remain competitive. If he decides to buy the engines from a supplier, he'll become 
dependant on the suppliers regarding a component of high importance. But those assessments are no explicit part of the game - by purpose. By not asking a player these questions, he is forced to consider all important inputs to a decision to prevent experiencing negative results as long term effects.

\section{CONCLUSION}

The presented approach of PRIME uses two important elements to support the training process of business professionals: The trainees act in a network, which is very important to create a sufficient complexity in the VBE especially since human players act not as predictable as simulation models or artificial stakeholders, which are only included to fill the VBE and guarantee a sufficient amount of active players. Besides, the fact that human players have to deal with each other makes negotiations more realistic and even the personal aspect of inter-organizational collaboration is automatically present. The second major element is the free decision making, which omits querying the player to react on discrete events. Instead the players have to be pro-active and maintain an overview over their virtual environment and assess the current situation.

Based on this concept, and combined with a good concept of integrating games into corporate trainings, the PRIME consortium is developing a game, which has high potential to address not only the grave background of a learning tool, but also to mediate fun while playing. This way the PRIME game will increase the motivation of the trainees, since they will be able to play a game, even if it's just a supportive training activity.

\section{REFERENCES}

1. Baalsrud Hauge, J., Schwesig, M., Thoben, K.-D., Eschenbächer, J.: Business games - an effective tool for experiencing collaboration in production networks. pp. 30-37. In: Proceedings of the 9.th Workshop of IFIP W.G 5.7 - Special Interest Group on Experimental Interactive Learning in Industrial Management. Esbo, 2005.

2. Heide Smith, J.: The Problem of Other Players: In-game Cooperation as Collective Action. In: Proceedings of the DiGRA Digital Games Research Association Conference 2005

3. Herz, J.C., Macedonia, Michael R.: Computer Games and the Military: Two Views. Defense Horizons, Center for Technology and National Security Policy, National Defense University, April 2002

4. Linden Lab: Second Life. http://secondlife.com, Accessed: 09.03.2006

5. McLean, Charles, Jain, Sanjay, Lee, Y. T., Riddick, Frank, A: A Simulation and Gaming Architecture for Manufacturing Research, Testing, and Training. Proceedings in the IFIP 5.7 Advances in Production Management System Conference, Rockville, MD, September 18-21, 2005

6. Ondrejka, Cory: Changing Realities - User Creation, Communication, and Innovation in Digital Worlds. http://lindenlab.com/whitepapers/Changing_Realities_Ondrejka.pdf, 07.03.2006

7. Prensky, Marc: Digital Game-Based Learning. McGraw-Hill Companies, 2001

8. Schwesig, M., Thoben, K-D., Eschenbacher, J.: A Simulation Game Approach to Support Learning and Collaboration in Virtual Organisations. In: Proceedings of the 6th IFIP Working Conference on Virtual Enterprises, PRO-VE'05, Valencia, 2005

9. Serious Gaming Initiative, http://www.seriousgames.org/, Accessed: 05.03 .2006

10. Thoben et al:: Training through gaming - applying a simulation based business game to train people for collaboration in virtual enterprises. Online Educa Berlin 2005, 11. International Conference on Technology Supported Learning \& Training, 2005 